\title{
Contemporary documentation of the rare eastern North American species Inocybe insignis (Inocybaceae, Agaricales)
}

\author{
Michael Kuo', P. Brandon Matheny ${ }^{2}$ \\ I Department of English, Eastern Illinois University, 600 Lincoln Avenue, Charleston IL 61920 USA \\ 2 Department of Ecology and Evolutionary Biology, University of Tennessee, Hesler Biology Building 332, \\ Knoxville TN 37996-1610 USA
}

Corresponding author: Michael Kuo (michael@mushroomexpert.com)

Academic editor: K. Hosaka | Received 6 July 2015 | Accepted 20 October 2015 | Published 6 November 2015

Citation: Kuo M, Matheny PB (2015) Contemporary documentation of the rare eastern North American species Inocybe insignis (Inocybaceae, Agaricales). MycoKeys 11: 23-31. doi: 10.3897/mycokeys.11.5604

\begin{abstract}
Inocybe insignis, an eastern North American species with greenish blue staining basidiomes, is documented for the first time since its original description circa 75 years ago in the Great Smoky Mountains. Here, we provide a detailed macroscopic and microscopic description and photographs of this rarely collected species, based on material collected in an Illinois oak-hickory forest. Analysis of molecular phylogenetic data strongly supports an evolutionary alliance with Asian and Australasian species of the Inocybe asterospora group. The combination of stellate basidiospores, marginate stipe base, entirely pruinose stipe, rimose pileus, and strong distinctive odor corroborates the molecular results, but the closest relatives of $I$. insignis lack the greenish blue staining characteristic of I. insignis.
\end{abstract}

\section{Key words}

Bluing species, rare fungi, systematics, taxonomy

\section{Introduction}

Inocybe insignis Smith was described in 1941 on the basis of a collection of a single basidiome, made in Aug. 1938 (AHS 9781, held in MICH) in the Great Smoky Mountains National Park in Tennessee. Smith noted that " $[\mathrm{t}]$ he species is known only from the 
type," and that it "possesses so many unusual characters that it would be difficult to confuse it with any other Inocybe" (p. 12). The combination of stellate basidiospores, presence of pleurocystidia, and green to blue bruising is apparently unique; better-known bluing species like I. calamistrata (Fr.: Fr.) Gill. feature smooth spores and lack pleurocystidia. Other bluing species with smooth basidiospores and pleurocystidia include I. corydalina Quél. and allies and I. aeruginascens Babos (Kosentka et al. 2013); these species, however, exhibit their bluing reaction due to presence of hallucinogenic secondary metabolites (Kuyper 1986). Beyond the holotype collection, we find no records of further Inocybe insignis collections in American herbaria, despite Smith's inclusion of the species in a popular identification resource, How to Know the Gilled Mushrooms (Smith et al. 1979). The collection described in the present work was made in 2011 from central Illinois and consists of about a dozen basidiomes.

\section{Methods}

Collection of fresh basidiomes followed methods in Kuo and Methven (2014). Colors were recorded and codified following HEX codes displayed on a 2013 iMac with Intel Iris Pro graphics, using GNU Image Manipulation Program (GIMP) 2.8.10. Microscopic features were studied using hand sections of fresh material, and of dried specimens rehydrated in water after immersion in $90 \%$ alcohol. Sections were mounted in $2 \% \mathrm{KOH}$, Melzer's reagent, and lactophenol and cotton blue, and viewed using a Nikon Alphaphot YS microscope. Specimens are deposited in the New York Botanic Garden (NY) and the University of Tennessee Fungus Herbarium (TENN). Herbaria are cited according to Thiers (continuously updated).

DNA was extracted and sequenced from a recently dried basidiome following protocols outlined in Judge et al. (2010). Three nuclear gene regions were amplified: the internal transcribed spacers (ITS) of the ribosomal RNA operon, the first $1350 \mathrm{bp}$ of the large subunit ribosomal RNA (nLSU), and the second largest subunit of RNA polymerase II (rpb2) between conserved domains six and seven. For the LSU region, primers LR0R and LR7 were used for PCR and sequencing, in addition to use of LR5 as a sequencing primer, as in Baroni and Matheny (2011). DNA sequences of I. insignis have been released on GenBank (KP170913, KM245989). Destructive sampling of the holotype collection at $\mathrm{MICH}$ was avoided since the collection is represented by a single specimen.

All sequences were concatenated into a DNA sequence alignment in MacClade (Maddison and Maddison 2005). Based on BLASTn searches of sequences available in GenBank, taxa were sampled with affinities to Inocybe asterospora Quél. Sequences of Inocybe mixtilis (Britzelm.) Sacc. were used for rooting purposes as it is known this species diverged outside the I. asterospora group (Matheny et al. 2009, Ryberg et al. 2012). A GTR model of molecular evolution was used, together with an invariant proportion of sites parameter and gamma distributed rate heterogeneity, using Maximum Likeli- 
hood (ML) in the program RAxML 7.2.8 (Stamatakis 2006). 500 bootstrap replicates were employed to evaluate the statistical significance of groupings within the resulting best ML tree. The concatenated alignment is available at http://www.bio.utk.edu/matheny/Site/Alignments_\%26_Data_Sets.html or by request from the authors.

\section{Results}

Although an ITS amplicon was produced for I. insignis, heterogeneity in both spacers precluded direct sequencing of this product. Eight coding sites within the rpb2 gene region sequenced were found to be polymorphic, seven of which are silent. One polymorphic site was observed in the nLSU gene region sequenced.

The molecular dataset contains sequences from 19 vouchered specimens (Table 1) and 2874 included sites. 28 sites of the ITS region were too ambiguous to align and were thus omitted before phylogenetic analysis. ML analysis supports the autonomous status of Inocybe insignis in the I. asterospora group (Fig. 1). The species is most closely related to a well-supported cluster of Australasian and southeast Asian species (Horak et al. 2015) characterized by a suite of similar characteristics: stellate basidiospores, entirely pruinose stipe, marginate stipe base, thick-walled pleurocystidia, rimose or strongly rimose pileus surface, and generally distinctive odor (spermatic).

Table I. Taxon sampling and DNA sequences used in this study.

\begin{tabular}{|c|c|c|c|c|}
\hline \multirow{2}{*}{ Species } & \multirow{2}{*}{ Specimen-voucher } & \multicolumn{3}{|c|}{ GenBank accession no. } \\
\hline & & ITS & LSU & $r p b 2$ \\
\hline \multirow{2}{*}{ I. asterospora aff. } & DJLTN06-58 (TENN) & - & JN974975 & - \\
\hline & PBM3309 (TENN) & - & KM197215 & KM245976 \\
\hline \multirow{2}{*}{ I. asterospora $\mathrm{cf}$. } & MR00015 & AM882897 & AM882897 & - \\
\hline & PBM2453 (TENN) & DQ404390 & AY702015 & - \\
\hline I. insignis & MK07101101 (TENN) & - & KP170913 & KM245989 \\
\hline \multirow{5}{*}{ I. mixtilis } & HL2002 (CANB) & KP308781 & KP170952 & KM406195 \\
\hline & PAM05103003 (TENN) & HQ585870 & HQ641113 & KM406197 \\
\hline & PAM07110104 (LIP) & HQ586872 & HQ641115 & KM406196 \\
\hline & PBM1315 (WTU) & - & AY380387 & AY337395 \\
\hline & NLB972 (PERTH) & KP308790 & KP170960 & KM406203 \\
\hline \multirow{2}{*}{ I. nobilissima ined. } & NLB974 (PERTH) & KP308791 & KP170961 & KM406204 \\
\hline & PBM3772 (TENN) & KP308789 & KP170959 & KM406202 \\
\hline \multirow{3}{*}{ I. pileosulcata } & DED8058 (SFSU) & EU600838 & EU600838 & KM406219 \\
\hline & DED8164 (SFSU) & GQ892996 & GQ892951 & - \\
\hline & TBGT10742 & KP308810 & KP170979 & KM406218 \\
\hline I. pileosulcata aff. & DED8163 (SFSU) & GQ892997 & GQ892952 & KM406219 \\
\hline \multirow{2}{*}{ I. vagata ined. } & PBM3187 (CANB) & KP641639 & KP171091 & KM656135 \\
\hline & PDD72861 & HM060326 & HM060325 & - \\
\hline Inocybe sp. & DED8044 (SFSU) & GQ892995 & GQ892950 & KM656121 \\
\hline
\end{tabular}




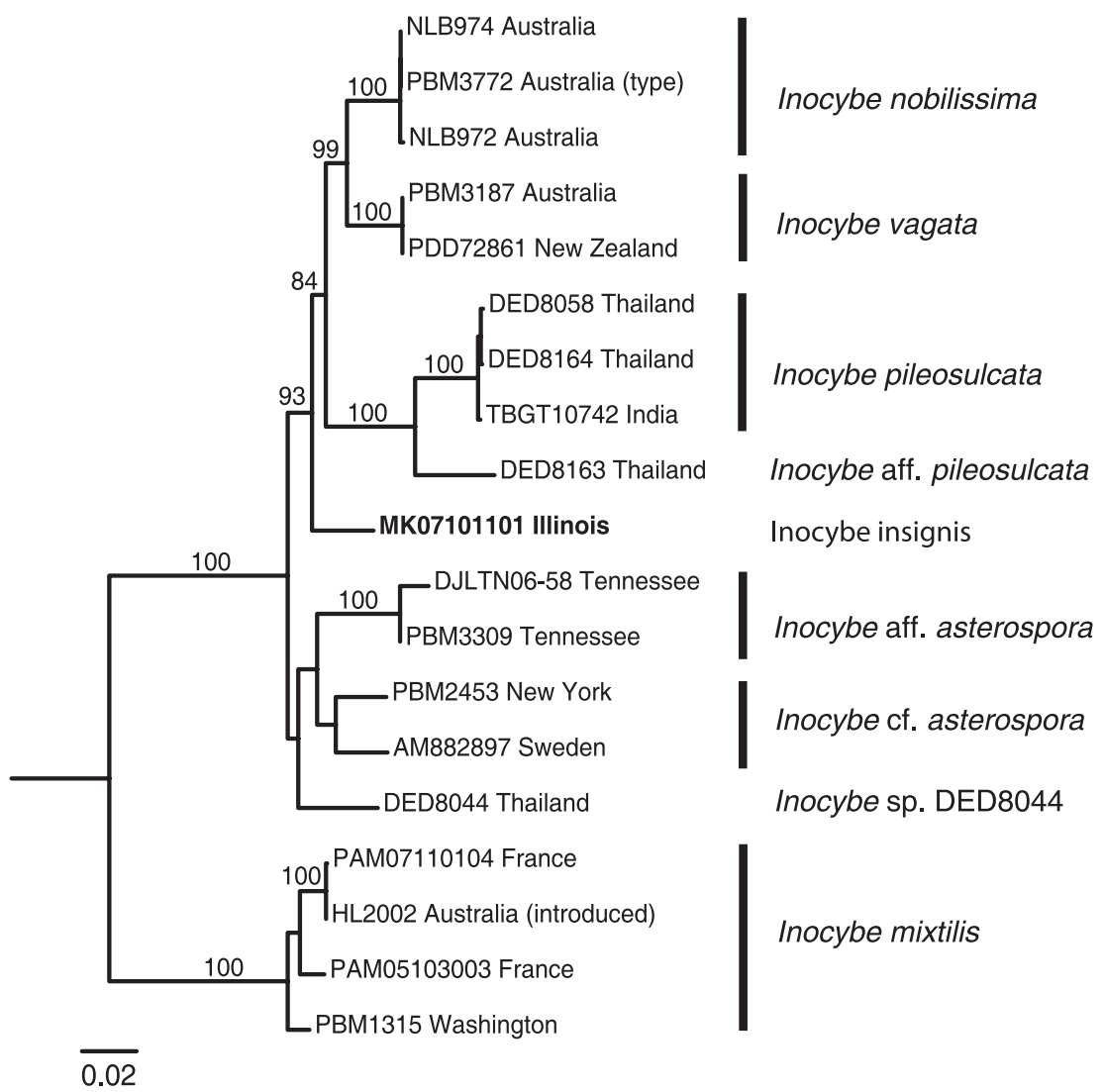

Figure I. Maximum likelihood tree for the Inocybe asterospora group. The tree is inferred from combined ITS-nLSU-rpb2 DNA sequence data. Values above branches represent bootstrap proportions (only those $>70 \%$ are shown). The scale bar represents the number of expected substitutions per site.

\section{Taxonomy}

\section{Inocybe insignis A. H. Smith}

MycoBank 278222

Inocybe insignis A. H. Smith, Mycologia 33: 11. 1941.

Type. United States of America. Tennessee, Sevier County: near Keener House, Great Smoky Mountains National Park, under mixed beech and hemlock, 3 Aug 1939, A. H. Smith 9781 (MICH 11068, non vide).

Pileus 30-60 mm broad; conic to obtusely conic at first, becoming broadly conic to applanate, with a broad, low umbo; surface dry, radially appressed fibrillose, becoming radially rimose, finely squamulose over the disc, dull brown (664139) to medium orangish brown (784333), with a slightly darker center, bruising greenish blue (445253), negative with the application of $15 \% \mathrm{KOH}$; context up to $7 \mathrm{~mm}$ thick 
on the disc, whitish, unchanging or slowly turning greenish blue on exposure; odor strongly sweet and fragrant, with a spermatic component; taste not assessed. Lamellae adnate to uncinate; close; with several tiers of lamellulae; at first buff (ded1e2), becoming dull cinnamon brown $(904 \mathrm{e} 2 \mathrm{e})$; occasionally staining greenish blue where bruised; edges concolorous, not conspicuously fimbriate. Stipe 50-70 × 3-4 mm; equal above a rimmed, bulbous base; surface dry, densely pruinose the entire length; cortina not observed and presumably absent; dull brown (664139) to pinkish brown (ad8796), bruising greenish blue to blackish blue (33363d); basal bulb 6-8 mm broad, subglobose, rimmed, whitish; basal mycelium whitish; context dull cinnamon brown (735c3a), unchanging or slowly turning greenish blue on exposure, becoming hollow.

Basidiospores 8-11 × 6-9 $\nabla \mathrm{m}$ (including nodules); average $\mathrm{Q}=1.23$; subelliptic to subcruciate or irregular in outline; stellate or prominently nodulose, with 7-11 conic to subconic nodules visible; ochraceous to golden or brownish in $\mathrm{KOH}$; orangish in Melzer's reagent; not cyanophilic. Basidia 35-40 × 8-11 $\bigotimes \mathrm{m}$; clavate to subclavate; 4-sterigmate; hyaline in $\mathrm{KOH}$; not reviving well after sporulation. Pleurocystidia 50-65 × 15-23 \m; widely lageniform or, less commonly, subcylindric, subutriform, or subglobose, with a short basal pedicel; thick-walled (walls 1-3 $\nabla$ m thick), hyaline in $\mathrm{KOH}$; apices crystalliferous; frequent. Cheilocystidia similar to pleurocystidia, frequent; paracystidia 20-30 × 5-8 $\nabla \mathrm{m}$, clavate to abruptly clavate, thin-walled, hyaline in $\mathrm{KOH}$, basally clamped. Lamellar trama parallel, hyphae 4-15 冈m wide, hyaline in $\mathrm{KOH}$; elements of subhymenium narrow and cylindric, 1-2 $\mathbf{m}_{\mathrm{m}}$ wide. Caulocystidia 55-75 × 12-20 $\mathrm{\Xi m}$, similar to hymenial cystidia, in fascicles with paracystidia, frequent near stipe apex, less frequent near stipe base; elements of stipe trama parallel, 3-10 $\bigotimes_{\mathrm{m}}$ wide, smooth, hyaline in KOH. Pileipellis a radially oriented cutis; hyphae cylindric, 2-7 $\otimes_{\mathrm{m}}$ wide, walls smooth or finely encrusted, hyaline to brown in $\mathrm{KOH}$, often clamped; cells of pileal trama 5-15 $\triangle \mathrm{m}$ wide, cylindric to somewhat inflated, smooth, hyaline to brownish in $\mathrm{KOH}$, septate, clamped, walls 0.5-1 $\bigotimes_{\mathrm{m}}$ thick. Clamp connections present.

Distribution. Eastern North America; central Illinois and east Tennessee.

Ecology. Growing scattered and gregariously on mossy soil under Carya glabra (Mill.) Sweet, Acer saccharum Marsh., Quercus velutina Lam., Quercus imbricaria Michx., and Carya ovata (Mill.) K. Koch. July. Fruiting in June (type recorded in August).

Conservation status. None. Known only from two collections.

Specimen examined. United States of America. Illinois: Shelby County, Hidden Springs State Forest, 39¹8.59'N; 8841.29'W, 10 Jun 2011, M. Kuo 07101101 (NY, TENN 066447).

Discussion. The Illinois collection described agrees with the macroscopic description of Smith (1941) in all details except the "somewhat bulbous base" recorded by Smith (basidiomes in Kuo 07101101 feature prominent, rimmed basal bulbs) and the color of the bruising, recorded by Smith as "greenish," "sordid green," and "sordid greenish gray" (basidiomes in Kuo 07101101 bruised greenish blue to blackish blue). The microscopic features recorded by Smith are also in agreement with those of Kuo 07101101, except for a slight difference in basidiospore morphology; Smith recorded 

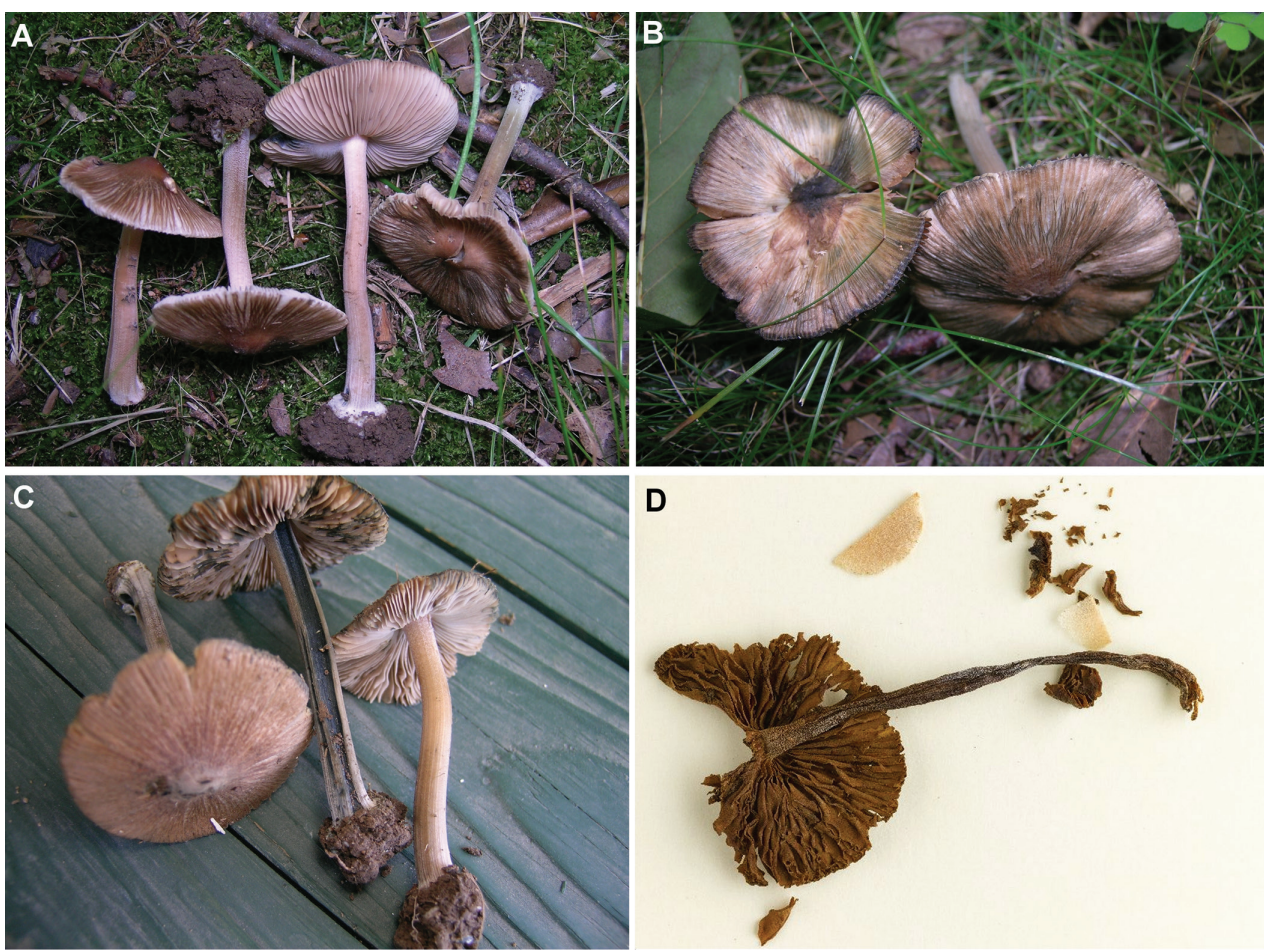

Figure 2. Basidiomes of Inocybe insignis (Kuo 07101101). A-C Kuo 07101101 D Holotype collection (A.H. Smith 9781, held in MICH); The Regents of the University of Michigan, Ann Arbor, MI 48109. Used with permission. Contact the University of Michigan Herbarium for details.

spores with dimensions of "(8) 9-12 × (6) 7-10 区" and 9-13 nodules, somewhat larger than the Illinois collection. Aside from these subtle differences, we find our current collection in complete agreement with the description of the type, which consists of but a portion of a single basidiome. While it is not possible to draw conclusions about the demographics of this species (now known from only two collections), we did observe genetic heterogeneity in all three gene regions sequenced.

Based on a multi-gene phylogenetic analysis (Fig. 1), I. insignis is most closely related, and indeed the sister group to, a small consortium of species from southeast Asia and Australasia. Inocybe pileosulcata E. Horak, Matheny \& Desjardin has been recorded from Thailand and Malaysia in association with a wide assortment of ectomycorrhizal plant associates (Dipterocarpus, Shorea, Castanopsis, Pinus) in tropical lowland and montane forests (Horak et al. 2015). We are also aware of this species from dipterocarp forests in tropical regions of India. The two provisionally named Australasian species, I. vagata Matheny \& Bougher ined. (=I. asterospora sensu E. Horak) and I. nobilissima Matheny \& Bougher ined., occur in Australia and/or New Zealand, and have been recorded in forests dominated by sclerophyll vegetation (Eucalyptus, Leptospermum, Allocasuarina, Acacia) and/or mixed with Nothofagus in New Zealand. Despite the wide geographical disjunction in this group, all of these species share the presence of 

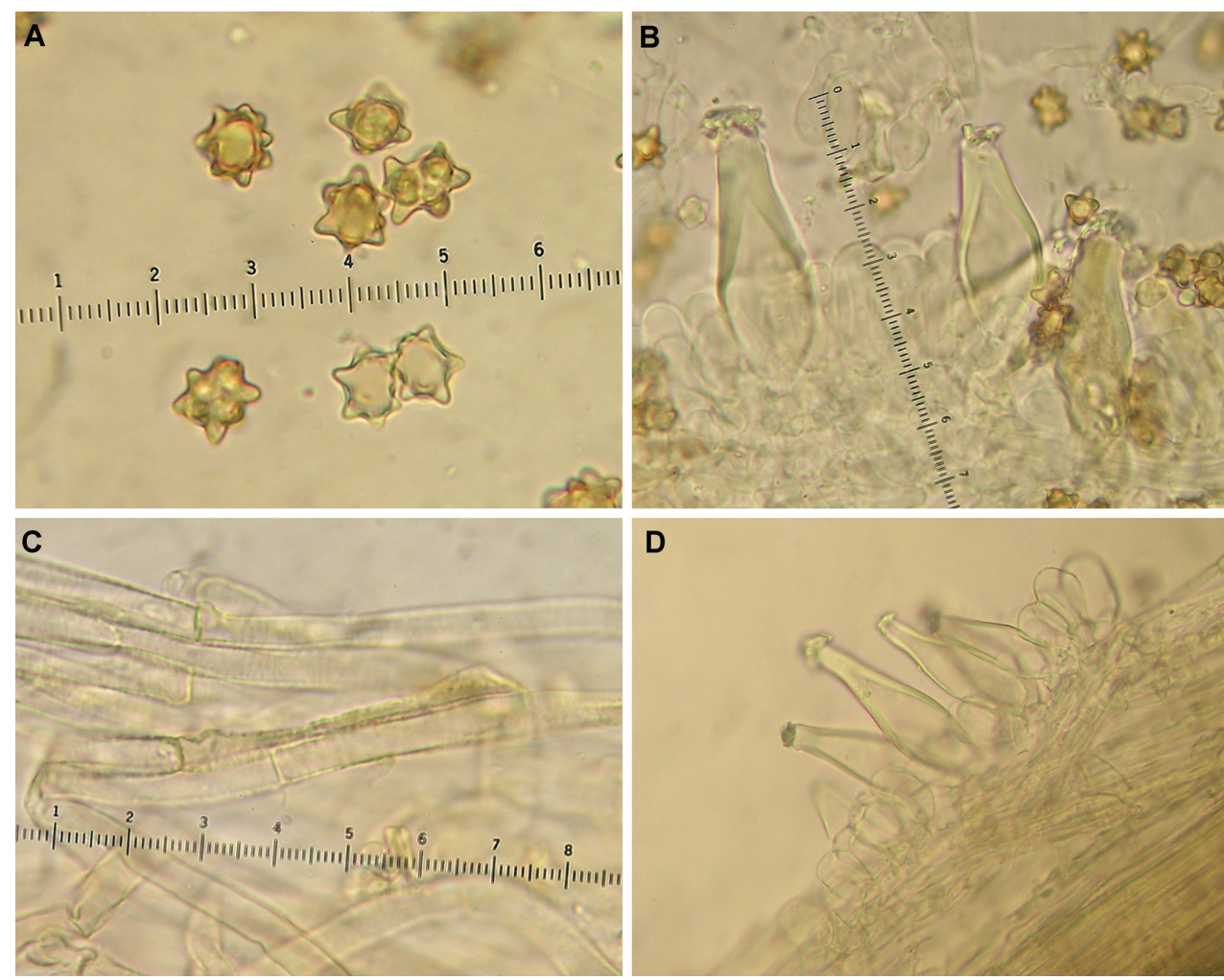

Figure 3. Microscopic features of Inocybe insignis (Kuo 07101101). A Basidiospores B Basidiospores and cheilocystidia C Pileipellis hyphae D Caulocystidia and cauloparacystidia.

stellate-shaped basidiospores, distinct marginate basal bulb, and conspicuous odor, typically spermatic. All three Australasian and Asian species discussed above lack the strong sweet smell (but with a spermatic component) and the greenish blue staining of basidiomes that characterize I. insignis.

Collections of Inocybe xanthomelas Boursier \& Kühner could possibly be confused with $I$. insignis due to their discoloration to a fuscous or grayish black color especially after drying. However, I. xanthomelas does not discolor greenish blue or blackish blue, nor is it closely related phylogenetically to I. insignis. Other species from Europe have been documented with nodulose spores, a marginate stipe base, and flesh that changes color, particularly upon drying. The taxonomic status of these species has been addressed by Esteve-Raventós et al. (2015), but none of these have the stellate spores that characterize I. insignis, and all are phylogenetically remotely related to the I. asterospora group (Ryberg et al. 2010).

The biogeographical relationship exhibited here (Fig. 1) - a disjunct relationship between eastern North America and southeast Asia and Australasia - is one not often recorded in mushroom-forming fungi. Disjunct relationships between eastern North America and temperate east Asian species have been suggested in various groups of 
macrofungi (Wu and Mueller 1997; but see Mueller et al. 2001) and between eastern North America and the Caribbean (Baroni et al. 1997). In other groups some cohesion between Asia and western North American macrofungal species has been reported (Petersen and Hughes 2003). A group worthy of investigation that might share a similar southeast Asia/Australasia-eastern North American disjunct is Gloeocantharellus (Corner 1969, Giachini et al. 2010). However, northern South American species have also been ascribed to Gloeocantharellus, and this element is apparently missing from the $I$. asterospora group.

\section{Conclusion}

The combination of outstanding taxonomic features-the greenish blue staining of basidiomes, stellate spores, rimose pileus, stipe with a marginate basal bulb, and strong odor-affirms the identity of this rare agaric as Inocybe insignis. This is the first report of this unusual species since it was described in 1941 from east Tennessee. Molecular phylogenetic analysis confirms close evolutionary relationships to Australasian and Asian species in the Inocybe asterospora group.

\section{Acknowledgements}

We are grateful to Melissa Kuo for help with collection and documentation. We also thank Joseph Ammirati, Cathy Cripps, Roy Halling, Jay Justice, Patrick Leacock, David Lewis, Andrew Methven, The University of Michigan Herbarium, Patricia Rogers, Ron Petersen, and Matthew Smith for invaluable assistance in various aspects of this study. The second author would like to acknowledge grant support from the National Science Foundation (NSF-DEB-1354802).

\section{References}

Baroni TJ, Lodge DJ, Cantrell SA (1997) Tropical connections: sister species and species in common between the Caribbean and the eastern United States. McIlvainea 13: 4-19.

Baroni TJ, Matheny PB (2011) A re-evaluation of gasteroid and cyphelloid species of Entolomataceae from eastern North America. Harvard Papers in Botany 16: 293-310. doi: $10.3100 / 0.25 .016 .0205$

Corner EJH (1969) Notes on catharelloid fungi. Nova Hedwigia 18: 783-818.

Esteve-Raventós F, Moreno G, Bizio E, Alvarado P (2015) Inocybe flavobrunnescens, a new species in section Marginatae. Mycological Progress 14: 14. doi: 10.1007/s11557-015-1036-0

Giachini AJ, Hosaka K, Nouhra E, Spatafora J, Trappe JM (2010) Phylogenetic relationships of the Gomphales based on nuc-25S-rDNA, mit-12S-rDNA, and mit-atp6-DNA combined sequences. Fungal Biology 114: 224-234. doi: 10.1016/j.funbio.2010.01.002 
Horak E, Matheny PB, Desjardin DE, Soytong K (2015) The genus Inocybe (Inocybaceae, Agaricales, Basidiomycota) in Thailand and Malaysia. Phytotaxon 230(3): 201-238. doi: 10.11646/phytotaxa.230.3.1

Judge BS, Ammirati JF, Lincoff GH, Trestrail JH, Matheny PB (2010) Ingestion of a newly described North American mushroom species from Michigan resulting in chronic renal failure: Cortinarius orellanosus. Clinical Toxicology 48: 545-549. doi: $10.3109 / 15563650.2010 .495346$

Kosentka P, Sprague SL, Ryberg M, Gartz J, May AL, Campagna SR, Matheny PB (2013) Evolution of the toxins muscarine and psilocybin in a family of mushroom-forming fungi. PLoS ONE 8(5): e64646. doi: 10.1371/journal.pone.0064646

Kuo M, Methven AS (2014) Mushrooms of the Midwest. University of Illinois Press, Urbana, Illinois.

Kuyper TW (1986) A revision of the genus Inocybe in Europe. I. Subgenus Inosperma and the smooth-spored species of subgenus Inocybe. Persoonia 3(Suppl.): 1-247.

Maddison DR, Maddison WP (2005) MacClade 4: version 4.08 for OS X. Sinauer Associates, Sunderland, Massachusetts.

Matheny PB, Aime MC, Bougher NL, Buyck B, Desjardin DE, Horak E, Kropp BR, Lodge DJ, Soytong K, Trappe JM, Hibbett DS (2009) Out of the palaeotropics? Historical biogeography and diversification of the cosmopolitan ectomycorrhizal mushroom family Inocybaceae. Journal of Biogeography 36: 577-592. doi: 10.1111/j.1365-2699.2008.02055.x

MyCoPortal (continuously updated) Mycology Collections Data Portal. http://mycoportal.org

Petersen RH, Hughes KW (2003) Phylogeographic examples of Asian biodiversity in mushrooms and their relatives. Fungal Diversity 13: 95-109.

Ryberg M, Larsson E, Jacobsson S (2012) An evolutionary perspective on morphological and ecological characters in the mushroom family Inocybaceae (Agaricomycotina, Fungi). Molecular Phylogenetics and Evolution 55: 431-442. doi: 10.1016/j.ympev.2010.02.011

Smith AH (1941) New and unusual agarics from North America. II. Mycologia 33: 1-16. doi: $10.2307 / 3754730$

Smith AH, Smith HV, Weber NS (1979) How to know the gilled mushrooms. Wm. C. Brown, Dubuque, Iowa.

Stamatakis A (2006) RAxML-VI-HPC: maximum likelihood-based phylogenetics with thousands of taxa and mixed models. Bioinformatics 22: 2688-2690. doi: 10.1093/bioinformatics/btl446

Thiers B (continuously updated) Index Herbariorum: a global directory of public herbaria and associated staff. New York Botanic Garden's Virtual Herbarium. http://sweetgum.nybg. org/ih/ [accessed June 2015]

Wu Q, Mueller GM (1997) Biogeographic relationships between the macrofungi of temperate eastern Asia and eastern North America. Canadian Journal of Botany 75: 2108-2116. doi: $10.1139 / \mathrm{b} 97-922$ 